\title{
POR QUE ESTÃO ME INTERNANDO? UM ESTUDO SOBRE OS CRITÉRIOS UTILIZADOS PARA A IMPOSIÇÃO DA MEDIDA SOCIOEDUCATIVA DE INTERNAÇÃO NA COMARCA DE SÃO BORJA
}

\author{
Adriana Hartemink Cantini ${ }^{1}$ \\ Vania Cristina Rodrigues Vitório ${ }^{2}$
}

\begin{abstract}
Resumo
A análise dos critérios utilizados pelo Juiz da Infância e Juventude para a aplicação da medida socioeducativa de internação ao adolescente em conflito com a lei é o tema deste estudo. Foram analisados três processos judiciais, com decisões transitadas em julgado, na Comarca de São Borja(RS), com sentenças prolatadas por juízes diferentes, onde houve internação. A legislação regente da matéria - Constituição Federal e Estatuto da Criança e do Adolescente-, erigiu o adolescente à condição de sujeito de direito, considerando-o Pessoa em peculiar condição de desenvolvimento, adotando um critério diferenciado para aplicação e execução da medida socioeducativa (Doutrina da Proteção Integral), ampliando a discricionariedade do Juiz da Infância e Juventude. Embora a vanguarda da doutrina, baseada em princípios fundamentais, dilui-se na aplicação efetiva ao caso concreto, pela utilização de parâmetros subjetivos do julgador que prescinde de elementos essenciais (circunstâncias), além da inobservância de referencial técnico emitido por outros profissionais, tal fato resulta em afronta a princípios norteadores do Estatuto da Criança e do Adolescente e ao cerceamento das inúmeras garantias ao adolescente infrator.
\end{abstract}

Palavras-chave: Adolescentes; Ato Infracional; Medida socioeducativa; Discricionariedade;

\section{INTRODUÇÃO}

"E., nasceu na cidade de São Borja - RS no dia x e hoje tem 15 anos de idade. Possui sete irmãos. Diz ter estudado até a terceira série do ensino fundamental. O pai é falecido e a mãe do lar, o padrasto é trabalhador rural. E. atirou em A.. A matou seu irmão que tinha 21 anos de idade [...] tem um irmão preso por assalto a mão armada e uma irmã presa por tráfico de drogas [...] E. não faz uso de drogas. Tem necessidade de tratamento psiquiátrico e psicológico". (Extraído do processo no $030 \backslash 3$, comarca de São Borja $\backslash R S$, data de julgamento $05 \backslash 2011)$

A história narrada no extrato supracitado, que dá início a este trabalho, é real. Os dados são de um laudo psicológico. O adolescente é autor de uma tentativa de homicídio. Sua vida, como de tantos jovens é marcada por

\footnotetext{
1 Doutora em Direito. Professora visitante da UNaM (Universidad Nacional deMisiones-AR). Professora Adjunta da UNIPAMPA, Campus São Borja (RS).E-mail: adrianacantini@unipampa.edu.br

2 Especialista em Serviço Social e Direitos Humanos pela UNIPAMPA - Universidade Federal do Pampa. E-mail: vcrvitorio@tj.rs.gov.br
} 
fatos comuns e outros, trágicos. Ao praticar o delito, surge a necessidade de responsabilização, embora ele tenha apenas 15 anos. É que o Direito brasileiro garante, a quem não tiver completado 18 anos, uma legislação especial diante da prática de delitos, que dá o nome de ato infracional. A esses, denominados inimputáveis, em vez de pena, recebem uma medida socioeducativa. Como será esse "caminho"? É sobre a aplicação da medida socioeducativa de internação a abordagem que será feita neste artigo.

É recorrente, seja na mídia, seja no cotidiano de qualquer cidade brasileira, casos como o acima narrados. São adolescentes que, por motivos variáveis, embora em condições sociais por vezes muito semelhantes, recebem medida socioeducativa de internação. Este debate tem se proliferado, sobretudo devido às recentes polêmicas acerca do que popularmente se denominou de "redução da maioridade penal" - a PEC (Projeto de Emenda Constitucional) 171/93, que pretende a alteração do dispositivo constitucional que garante a inimputabilidade aos menores de 18 anos para 16 anos, em caso de crimes hediondos, foi aprovada em segundo turno pela Câmara dos Deputados e encaminhada ao Senado em 21 de agosto de 2015, onde encontra-se, na Comissão de Constituição, Justiça e Cidadania desde 05/03/2017. O presente trabalho surgiu, então, da busca de respostas a esse e a tantos outros casos noticiados na mídia (como sem nenhuma responsabilização), além das indagações apresentadas durante as aulas do curso de Pós-graduação da Universidade Federal do Pampa em Serviço Social e Direitos Humanos na modalidade de Especialização. Esse estudo realizou uma análise sobre a discricionariedade do juiz na aplicação da medida socioeducativa de internação. Questionou-se como problema central da pesquisa, quais são os critérios utilizados pelo juiz da infância e juventude na aplicação da medida socioeducativa de internação, prevista no Estatuto da Criança e do Adolescente (ECA).

Para responder a indagação foram identificados 03 (três) processos com decisões transitadas em julgado na Vara da Infância e Juventude onde a sentença decidiu pela aplicação da medida socioeducativa de internação, por três juízes diferentes. Também se analisou nos referidos processos quantos e quais profissionais outros (que não o juiz) emitiram laudos e pareceres sobre os adolescentes em conflito com a lei, buscando-se o reconhecimento dos pontos comuns nos laudos e relatórios que indicaram a aplicação da medida socioeducativa de internação e o reconhecimento dos pontos comuns em cada laudo e relatório que indicaram a não aplicação da medida socioeducativa. E, finalmente ao analisar-se a sentença do juiz, observou-se o comportamento do magistrado em relação aos critérios apontados pelos demais profissionais (e identificados nos laudos e relatórios) para a aplicação da medida, levando-se em conta o limite do poder discricionário do juiz ao decidir pela aplicação da medida socioeducativa de internação.

Como método de abordagem do problema foi utilizado o método hipotético-dedutivo, que tem início na percepção das lacunas dos conhecimentos, formulando-se hipóteses e destas, através de inferências dedutivas, testam-se os fenômenos constantes das hipóteses. Partiu-se da hipótese inicial de que o juiz não considera os 
laudos e relatórios emitidos pela equipe multidisciplinar para proferir sua sentença. Realizou-se um estudo sobre os documentos legais que estabelecem os direitos da criança e do adolescente, com foco nos direitos humanos. Tais documentos foram a Convenção dos Direitos da Criança (1989), a Constituição Federal (1988), o Estatuto da Criança e do Adolescente (ECA) e o Código Penal Brasileiro que estabelece as diretrizes para fixação da pena. Além disso, como método de procedimento, usou-se o método funcionalista, destacadamente interpretativo, sendo suas conclusões baseadas na interpretação propriamente dita dos textos das sentenças analisadas, considerando as hipóteses definidas pelas pesquisadoras, com foco no problema inicial da pesquisa. Por fim, a pesquisa delineou-se como sendo do tipo bibliográfica e documental com abordagem qualitativa.

\section{FUNDAMENTAÇÃO TEÓRICA}

\section{Os Adolescentes como Sujeitos de Direitos Humanos}

O princípio da igualdade, aparentemente singelo firmado na Carta Magna brasileira, mais especificamente no artigo 5º, remete-nos, a uma breve e necessária digressão histórica, para que possamos justificar a escolha do tema do presente artigo, bem como sua relação estreita com a Declaração Universal dos Direitos Humanos.

Foi na concepção medieval de Pessoa que se iniciou a elaboração do princípio da igualdade essencial a todo ser humano, não obstante a ocorrência de muitas diferenças individuais ou grupais, de ordem biológica ou cultural. E é essa igualdade de essência da Pessoa que forma o núcleo de um outro conceito universal: o de Direitos Humanos - direitos comuns a toda a espécie humana -, a todo gênero humano, os quais, portanto, resultam da sua própria natureza, não sendo meras criações políticas.

A elaboração teórica do conceito de Pessoa, como sujeito de direitos universais, anteriores e superiores, por conseguinte, a toda ordenação estatal, adveio com a filosofia kantiana (Kant, na Paz Perpétua,) que pontuava a respeito de uma legislação cosmopolita, cujas estipulações fossem universais. O ser humano, pela primeira vez na história, passa a ser considerado, em sua igualdade essencial, como dotado de liberdade e razão, não obstante as múltiplas diferenças de sexo, raça, religião ou costumes sociais, a partir do período axial. Lançam-se, assim, os fundamentos intelectuais para a compreensão da Pessoa humana e para a afirmação da existência de direitos universais, porque a ela inerentes. Essa convicção de que todos os seres humanos têm direito a ser igualmente respeitados, pelo simples fato de sua humanidade, nasce vinculada a uma instituição social de capital importância: a lei escrita, como regra geral e uniforme, igualmente aplicável a todos os indivíduos que vivem numa sociedade organizada. Porém, foram necessários muitos séculos para constar em um documento global, a proclamação de que "todos os homens nascem livres e iguais em dignidade e direitos". (Declaração Universal dos Direitos 
Humanos, art. 10, 1948).

Assim, com o pilar basilar da igualdade entre as pessoas insculpido na lei escrita (através das legislações internacionais e gerais, como as declarações universais e convenções), surge o reflexo interno na maioria dos países com a elaboração de sua legislação própria (alicerçadas na Lei Maior). Nesse sentido, quando nos referimos à Pessoa enquanto sujeito de direitos simplesmente por ser humana, também incluímos aqui os "pequenos", que, em uma linguagem cotidiana, nos remetem, naturalmente à criança e ao adolescente. Essa é a atual compreensão da comunidade internacional, comprovada após vários documentos, entre declarações e convenções, surgidos no século XX, que passam a reconhecê-los como objeto de proteção (Declaração de Genebra) ou sujeito de direitos (Declaração de Direitos e Convenção sobre Direitos), sendo a Declaração dos Direitos da Criança, aprovado pela ONU em 1959, um divisor de águas por englobá-los na rede de proteção global.

Na esteira dessas legislações internacionais, o Brasil, ao promulgar a Constituição Federal de 1988 (Lei Magna), alicerçou-se nos princípios norteadores da legislação mundial, baseado na igualdade e dignidade da pessoa, erigindo o adolescente à condição de sujeito de direitos (Art.224). Essa mudança de paradigma da seara jurídica pátria culminou com a promulgação do Estatuto da Criança e do Adolescente (Lei no 8069 \90), legislação regulamentadora da norma constitucional, reconhecendo a prioridade absoluta da criança e do adolescente e a adoção da doutrina de proteção integral. Nos termos do art. $2^{\circ}$ do E.C.A. é adolescente a pessoa que tiver entre 12 (doze) e 18 (dezoito anos) incompletos, sendo a idade o fator determinante para a fixação da adolescência. Adota-se o critério cronológico absoluto, sem menção à condição psíquica ou biológica do sujeito. Essa limitação de idade nos permite aplicar na prática a denominada doutrina da proteção integral:

[...] a Doutrina da Proteção Integral reconhece que todas as crianças e adolescentes são detentores de todos os direitos que têm os adultos e que sejam aplicáveis à sua idade, além dos direitos especiais que decorrem, precisamente, da especial condição de pessoas em desenvolvimento. (LIBERATI, 2003, p.58).

Dessa forma, próprio Estatuto define o crime ou a contravenção como ato infracional, diferenciando o tratamento jurídico dado a ele, quando for cometido por adolescente. A definição extrai-se da própria legislação "considera-se ato infracional a conduta descrita como crime ou contravenção penal" (ECA, art.103).

Essa conceituação rompe a concepção de adolescente infrator como categoria sociológica vaga implícita no antigo Código de Menores, concepção que, amparando-se numa falsa e eufemística ideologia tutelar (doutrina da situação irregular), aceitava reclusões despidas de todas as garantias que uma medida de tal natureza deve necessariamente incluir e que implicavam uma verdadeira privação de liberdade. (VOLPI, 2006, p.15).

Estabelece-se uma diferenciação terminológica (meramente) entre ato infracional e delito, mas em parte importante: $\mathrm{o}$ ato infracional destina-se aos adolescentes (entre 12 e 18 anos incompletos); o delito aos adultos. A intenção da formulação legal é marcar a diferença de responsabilização e de tratamento jurídico quando se tratar de adolescente, inimputável até os 18 anos e sujeito à legislação especial (art.228, CF). Essa distinção, no Brasil, evoluiu até chegar à formulação atual do ECA que explicita a doutrina da proteção integral exposta no artigo 227 
da Constituição Federal, elevando-os à categoria de sujeitos de direitos à criança e o adolescente e dizendo que tem, ao menos em tese, prioridade absoluta.

Assim, o adolescente autor de ato infracional deverá ser julgado como Pessoa em desenvolvimento, com direitos específicos e não simplesmente pelo ato cometido, sendo submetido ao devido processo legal com todos os direitos correspondentes e ele, como direito à prova, à defesa qualificada, a não produzir prova contra si próprio, além dos princípios próprios da legislação como da legalidade, da individualização, da proporcionalidade (entre outros) devendo ser percebido a partir de sua condição de Pessoa em desenvolvimento, com possibilidades múltiplas de ressocialização e não somente castigado ou penalizado pelo ato infracional cometido por isso se prescreve a medida denominada de socioeducativa. "As medidas socioeducativas estão previstas no Estatuto da Criança e do Adolescente (ECA) e são aplicáveis aos adolescentes autores de ato infracional que em termos de lei é considerada a pessoa na faixa etária dos doze até os dezoito anos incompletos [...]”. (LAZZAROTTO, 2014, p. 165).

O intuito da aplicabilidade das medidas socioeducativas é o de responsabilizar o jovem infrator. Saraiva (2009) destaca que neste processo, o jovem em conflito com a lei, passou a fazer parte como sujeito de direitos e deveres, observando-se, entretanto, a sua fase de desenvolvimento, em relação à aplicação das medidas socioeducativas (diferentemente do estabelecido no Código Penal em relação aos imputáveis).

Conforme Matos (2011), somente serão aplicadas as medidas citadas no art. 112 do ECA, que são divididas em dois grupos: medidas socioeducativas em meio aberto (advertência, reparação do dano, prestação de serviços à comunidade e liberdade assistida) e medidas socioeducativas em meio fechado (semiliberdade e internação). Ele pode ainda ser inserido em programas de proteção, mencionados no art. 101 da referida lei. Dentre esses programas de proteção podemos destacar a inclusão em programa oficial ou comunitário de auxílio à família; à criança e ao adolescente; requisição de tratamento médico; psicológico ou psiquiátrico em regime hospitalar ou ambulatorial; inclusão em programa oficial ou comunitário de auxílio; orientação e tratamento a alcoólatras e toxicômanos, se ao jovem (autor de ato infracional) não for imposta uma medida socioeducativa pela prática de uma conduta típica.

[...] a prática de um ato tido como infracional, na sua grande maioria, é decorrente de uma ação inconsciente. Destarte, pode-se mesmo afirmar que uma parcela mínima de jovens tinha consciência do que realmente decidiam quando desencadeavam a sua atuação conflitante com a lei. As verificações de reincidência cometida por estes jovens podem ser ainda inconscientes, visto que se encontram em fase de desenvolvimento. Verifica-se que o simples ato de repreender estes adolescentes não é suficiente, nem auxilia em sua formação de caráter, é necessário um acompanhamento especializado para a formação de suas personalidades, fazendo com que o infrator compreenda por si mesmo que estes atos estão em desacordo com a legislação (RAMIDOFFI apud MATOS, 2011, p.15).

Os mandamentos que regulam a conduta externa do indivíduo possibilitando a atuação coativa, legitimada pelo poder estatal, são as normas jurídicas, utilizadas como meio para viabilizar a vida em sociedade 
(BOBBIO, 1999, p.27). Os elementos básicos que compõem essas normas são o preceito (comportamento que se espera do sujeito frente ao imperativo legal) e a sanção (consequência jurídica coercitiva imposta ao sujeito, pelo Estado, em virtude do descumprimento do preceito). (FERRAZJUNIOR, 1999, p.29).

A sanção punitiva deriva exclusivamente do descumprimento do preceito estabelecido, sendo a pena, esta sanção punitiva com caráter aflitivo (restrição a direitos fundamentais). À luz desse entendimento, segundo a doutrina dominante no Brasil, a medida socioeducativa, ontologicamente, é pena, possuindo natureza coercitiva.

Mesmo que haja uma finalidade socializadora, a persecução dessa finalidade, realiza-se mediante aflitividade, sendo que a resposta estatal a injustos praticados por adolescentes, considerando a própria gravidade da conduta, traz consigo, um caráter instrumentalmente repressivo (ainda que o objetivo seja reeducar e socializar). (SARAIVA, 2004, p. 138).

Considerando tais discussões, o artigo 112 do ECA estabelece as modalidades de medidas socioeducativas aplicáveis aos adolescentes autores de atos infracionais. $\mathrm{O}$ rol é taxativo e requer, um rigoroso nexo de causalidade entre a conduta praticada e o dano causado. Dentre este rol, a medida mais grave e severa, tendo em vista o grau de interferência do Estado na esfera de liberdade individual do adolescente, é a internação. Em função da gravidade da medida, mister se faz o cumprimento de três princípios para a sua validade: o princípio da brevidade, o da excepcionalidade e o do respeito à condição peculiar de pessoa em desenvolvimento. No dizer de Sposato,

[...] o princípio da excepcionalidade incide diretamente na fase de imposição pelo Poder Judiciário da medida mais adequada ao caso concreto, levando em conta as circunstâncias e a gravidade do ato praticado, e as condições de cumprimento da medida por parte do adolescente [...] o respeito à condição peculiar de desenvolvimento relaciona-se à necessária individualização da medida em atenção às características pessoais do jovem, e, como já mencionado, a sua capacidade de cumprir a determinação judicial, de tal forma que o cumprimento da internação atenda às exigências de acompanhamento personalizado. (SPOSATO, 2006, p.128)"

Ressalte-se que o ECA rege-se por princípios constitucionais norteadores, que são mandamentos nucleares do sistema de normas, valendo os mesmos direitos e garantias dos imputáveis aos adolescentes em conflito com a lei. Não obstante tal fato, alguns princípios não atingiram a observância plena na Justiça da Infância e Juventude. São eles: o Princípio da legalidade que é um princípio basilar do Estado Democrático de Direito e assegura a possibilidade de prévio conhecimento dos crimes e das penas (art.5o, XXXIX, CF) e o Princípio da Individualização que o Código Penal adota, o critério de individualização para a aplicação da pena, estabelecido no artigo 59, com o estabelecimento da pena com base nas atenuantes e agravantes, causas de aumento ou de diminuição. Já o ECA adotou mecanismos próprios, não instituindo os mesmos critérios temporais da legislação penal, adotando critérios subjetivos, não estabelecendo previamente as hipóteses condicionadas à aplicação de uma ou outra medida, nem tampouco disciplinando os pressupostos para a fixação do período em concreto da medida socioeducativa, fixando somente os prazos máximos e mínimos. Com essa sistemática, surge, inexoravelmente, a discricionariedade do julgador, ferindo o Estado Democrático de Direito (através do 
descumprimento de princípio norteador dessa Estado, que é o da legalidade), ocasionando, em vários julgados, decisões destoantes do espírito do ECA.

Tal sistema de aplicação de medida ocorre em virtude da observância da peculiar condição de desenvolvimento do destinatário da lei, que é o adolescente em conflito com a lei (ou deveria ser). Não obstante, o artigo $112, \$ 1^{\circ}$ do ECA estabelece que a medida socioeducativa aplicada ao adolescente levará em consideração a sua capacidade de cumpri-la, bem como as circunstâncias e a gravidade da infração,

[...] a previsão diferenciada, pretendida pelo Estatuto em relação a individualização da medida, o juiz da sentença não terá outros parâmetros de fixação da sanção, senão aqueles que, analisados em conjunto, consideram a capacidade do adolescente para cumpri-la, as circunstâncias e a gravidade da infração, conforme dispõe o seu art.112 $₫ 1^{\circ}$ (LIBERATI, 2006, p.135)

Mesmo não havendo precisão da legislação no estabelecimento dos parâmetros adotados pelo Juiz na fixação das medidas, o ECA elenca alguns elementos indispensáveis que ele deve considerar nesse momento como a conduta do infrator e o convívio familiar e social - o meio em que ele está inserido. Assim, um dos parâmetros a ser analisado pelo Magistrado é o próprio sujeito em formação, aplicando a medida mais benéfica conforme a sua capacidade de transformação e de incorporação de novos valores. Deve ser considerada a capacidade de cumprimento da medida em virtude do respeito ao princípio da peculiar condição de Pessoa em desenvolvimento, além das circunstâncias e a gravidade da infração (Art.112, \$1), incorporando neste artigo, outro princípio basilar: o da proporcionalidade.

Partindo inclusive do princípio de que nenhuma disposição estatutária pode ser interpretada ou aplicada em prejuízo do adolescente, a incidência deste parâmetro não importa, logicamente, na conclusão de que para todo ato de natureza grave deverão corresponder medidas privativas de liberdade. Mesmo em tais casos, somente deverá ocorrer à privação de liberdade quando não restar outra alternativa sócio-pedagógica (DIGÁCOMO,2006, p. 220)

Além disso, em consonância com o art. 100 do ECA, na aplicação das medidas deverão ser consideradas as necessidades pedagógicas, preferindo-se aquelas que fortaleçam os vínculos familiares e afetivos. Nesse sentido, o mesmo autor afirma que qualquer intervenção deve ser realizada com a colaboração da família que precisa ser orientada e receber apoio, inclusive, algumas vezes, substituída para que possa assumir suas responsabilidades, que no seu entender, não devem ser transferidas a outros e muito menos ao próprio Estado³

O Juiz após o recebimento da representação ofertada pelo Ministério Público, em virtude de cometimento de ato infracional (investigado pela Polícia Judiciária - Polícia Civil) por adolescente instaurará o devido processo legal, com todas as garantias inerentes e, em conclusão, verificará a responsabilidade penal juvenil através da sentença. Nessa, analisará a ação que deverá ser típica, antijurídica e reprovável (elementos normativos

\footnotetext{
${ }^{3}$ A propósito dessa afirmação a Lei 12.594 de 18 de janeiro de 2012 que institui o Sistema Nacional de Atendimento Socioeducativo (SINASE), regulamenta a execução das medidas socioeducativas destinadas a adolescente que pratique ato infracional, sem eu artigo 35 estabelece os princípios que devem reger a execução das medidas socioeducativas em especial o inciso
} 
da culpabilidade) julgando procedente (ou improcedente) a pretensão deduzida pelo Ministério Público afirmando (ou negando) a responsabilidade do autor do fato e aplicando-lhe a medida socioeducativa adequada (no caso de procedência), observando, como já salientado, a capacidade do adolescente para o seu cumprimento, as circunstâncias e a gravidade da infração. Na sentença deverá, além de se pronunciar sobre o modo de execução da medida imposta, observar todos os requisitos elencados no artigo 381 do CPP (Código de Processo Civil), apresentando relatório, fundamentação e dispositivo, analisando todas as circunstâncias de fato e de direito atinentes ao tema em questão.

A sistemática estabelecida no ECA é diferente da estruturação do Código Penal brasileiro, que prevê o modus operandi da fixação da pena e a sua execução, em estrita observância ao Princípio da Legalidade (limitando a intervenção do Estado na liberdade do indivíduo). Parte da doutrina entende que não há violação ao Princípio da Legalidade em virtude da discricionária atuação do Magistrado, não sendo esta arbitrária. No entanto, outra parte, a qual defendemos, vislumbra a abstração dos parâmetros para a aplicação da medida, ferindo o Princípio da Legalidade e o da Individualização, porquanto não estabelecem restrições efetivas para a autoridade judiciária na aplicação das medidas socioeducativas. Este também é o entendimento Liberati revelando que,

Admitir um microssistema de imposição de sanção penal, mesmo que nominada taxativamente, como é o caso do art.112 do ECA - e, num segundo momento recusar, o legislador, a estabelecer critérios mais objetivos em seus termos iniciais e finais e de deixar, ao exclusivo critério do juiz, a escolha da medida "mais adequada" ao caso concreto, possibilita a violação do direito individual do adolescente de ter um sistema fixo e previsível de sanções individualizadas (LIBERATI. 2006, p. 158).

Não obstante a divisão doutrinária, outro aspecto relevante, senão imprescindível, no manejo do artigo112, $\mathbb{1} 1^{\circ}$ é domínio da linguagem interdisciplinar, assegurada pela participação de profissionais de outras áreas como psicologia, psiquiatria, pedagogia e serviço social, entre outros, na busca da materialização da finalidade pedagógica da medida, através de avaliação interdisciplinar. Ressalte-se que essa avaliação é facultativa, mas é somente através dela é que o julgador irá ter os elementos básicos e suficientes para a elaboração de seu julgado, como condição familiar, condição subjetiva do sujeito, meios financeiros, participação na comunidade, entre outros. O juízo do Magistrado, evidentemente, será lançado pela formação de sua convicção decorrente dos fatos e de todo o procedimento judicial, nesse sentido,

Evidentemente o julgador irá lançar seu juízo de acordo com a conviç̧ão que dos autos decorre. Todavia não poderá negar ao adolescente em julgamento a oportunidade de, através da intervenção de técnicos, verificar-se, sob um olhar psicossocial suas condições pessoais e sociais em face da decisão que necessariamente será lançada visando aferir a capacidade de cumprimento da medida e a utilidade desta" (SARAIVA, 2010, p.253)

A indispensabilidade do laudo, embora já tenha sido orientação dominante no Tribunal de Justiça do Rio Grande do Sul, hoje não mais prevalece. Nesse sentido: Apelação Cível 70063219299 - TJRS, 7a Câmara

IX que remete ao "fortalecimento dos vínculos familiares e comunitários no processo socioeducativo." 
Cível,

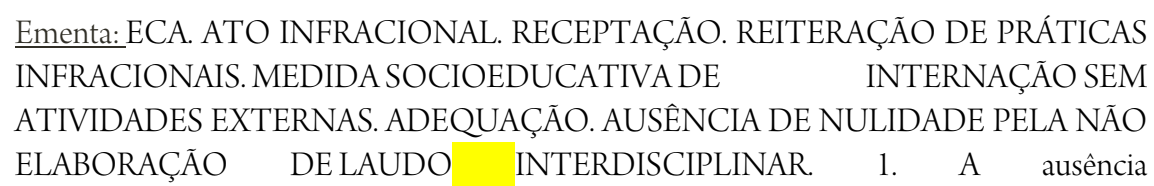
de laudo interdisciplinar não gera nulidade, pois determinar a sua elaboração constitui mera faculdade do julgador. Inteligência da conclusão $\mathrm{n}^{\circ} 43$ do CETJRS. 2. Comprovadas a autoria e a materialidade do ato infracional, torna-se imperiosa a procedência da representação e a aplicação da medida socioeducativa compatível com a gravidade do fato e com as condições pessoais do infrator. 3. Ainda que o fato descrito na exordial isoladamente não justificasse a aplicação da medida extrema, o grau desajuste pessoal do infrator, que revela ousadia e total falta de limites e de senso crítico, e vem reiterando em práticas infracionais, recomenda a imposição da medida socioeducativa de internação, pois as medidas anteriores em meio aberto se mostraram ineficazes. 4. Mostra-se necessária a adoção da medida de internação por se tratar de jovem que necessita ser retirado do meio onde vive, que é propício a novos deslizes, a fim de receber o amparo psicológico e social de que necessita para compreender a censurabilidade da sua conduta. 5. A adoção da medida extrema convidará o jovem infrator a rever sua conduta e repensar seus atos, tomando consciência de que existem limites que devem ser observados na vida social e que o direito das demais pessoas deve ser respeitado, sob pena de, brevemente, tornar-se inquilino do sistema prisional do Estado. Recurso desprovido. (Apelação Cível № 70063219299, Sétima Câmara Cível, Tribunal de Justiça do RS, Relator: Sérgio Fernando de Vasconcellos Chaves, Julgado em 25/02/2015)

Mesmo que seja "mera faculdade do julgador", tal fato, vai de encontro à linhagem estabelecida pelo ECA - doutrina da proteção integral -, suprimindo direito essencial, qual seja, a real aferição da capacidade do adolescente de cumprir a medida e a utilidade da mesma ("olhar psicossocial, no dizer de SARAIVA, 2010, p. 253).

\section{A ROTA PROCEDIMENTAL}

Em dezembro de 2016 eram cerca de 377 (trezentos e setenta e sete) os processos judiciais em andamento na Vara da Infância e da Juventude da Comarca de São Borja (englobando todos as matérias afetas à Infância e Juventude, excluídas ações de guarda e visitação que são da competência das Varas Cíveis). Desse universo extraiu-se uma amostra de três processos judiciais, cujos critérios de inclusão e exclusão foram: a) ter trânsito em julgado (decisão não mais sujeita a recurso) e, b) envolver medida socioeducativa de internação aplicada por juízes diferentes. A amostra final dos três processos foi obtida por conveniência da pesquisadora, sendo de livre escolha e mais fácil acesso, já que é servidora estadual, lotada na comarca de São Borja (RS).

Além disso, elaborou-se um roteiro de tópicos-guia como instrumento norteador da coleta de dados, tendo em consideração os objetivos inicialmente traçados e a hipótese da pesquisa. Analisou-se, outrossim, quantos e quais profissionais (que não o juiz) emitiram laudos e pareceres nestes processos sobre o adolescente em conflito com a lei, bem como, o reconhecimento dos pontos comuns em cada documento que indicou a aplicação da medida socioeducativa de internação ou a sua não- aplicação. Por derradeiro, analisou-se a sentença 
do Magistrado, considerando os critérios utilizados pelos demais profissionais (e identificados nos laudos) para a aplicação da medida e \ou quais critérios o Juiz utilizou para aplicação da mesma.

Os dados foram interpretados com base na análise textual-discursiva, que é "[...] caracterizada como uma metodologia na qual, a partir de um conjunto de textos ou documentos, produz-se um meta-texto, descrevendo e interpretando sentidos e significados que o analista constrói ou elabora a partir do referido corpus". (MORAES, 2003, p.202)

A leitura e interpretação dos processos foi autorizado pelo Juiz de direito da Vara da Infância e Juventude da Comarca de São Borja e as condições de sigilo e resguardo da privacidade das pessoas foram preservadas. Não serão divulgados nomes ou dados que possam levar à identificação das partes envolvidas nos processos judiciais, assim, os nomes foram substituídos por iniciais ficcionais e os números do processos foram suprimidos. Para uma melhor compreensão, inicialmente apresenta-se um breve resumo dos processos judiciais pesquisados que serão analisados no decorrer do trabalho.

1. Proc. № 030 \1-ROUBO- Ato infracional: Art. 157, \$2º I do C.P.- L., 16 anos. Autor: MP -Justiça Publica. Relato: "No dia x em via pública em São Borja, L. subtraiu para si, visando a lucro fácil, mediante grave ameaça exercida com emprego de uma faca (não apreendida), 01 aparelho celular de A res furtivae não restou apreendida (...) avaliada indiretamente em $\mathrm{R} \$ 250,00$ (...).”

2. Proc. $n^{\circ} 030 \backslash 2$ - TENTATIVA DE HOMICÍDIO: Art.121,\$2 , inciso IV $c \backslash c$ art.14, inciso II do CP L. ,16 anos e A., 16 anos. Relato: "No dia x, em via pública, em São Borja, L. e A., em comunhão de vontades e conjugação de esforços, mediante golpes de faca(apreendida), de soqueira e socos, tentaram matar (...)".

3. Proc. No 030/ 3 - TENTATIVA DE HOMICÍDIO QUALIFICADO: Autor do fato: E.- 15 anos. Relato: "No dia x em São Borja, E., tentou matar M., mediante 03 (três) disparos de arma de fogo (não apreendida), causando-lhe as lesões descritas no auto de exame de corpo de delito de $\mathrm{fl}$ x (...)." Foi deferida a internação provisória de 45 dias em virtude de Representação da autoridade policial, conforme artigos 112 e 122 da Lei $8068 \backslash 90$ e artigo 121,\$2 I e IV c $\backslash$ com art.14,II do CP. O menor foi encaminhado à FASE (Fundação de Atendimento Socioeducativo).

Os autores dos atos infracionais tinham à época do fato entre 15 e 16 anos, sendo que as ações foram interpostas nos anos de 2008, 2012 e 2013. As condições afetas as suas vidas são inicialmente perguntadas na Delegacia de Polícia Civil, onde é emitido o Boletim sobre a Vida Pregressa (informando sobre a profissão, estudo, se é arrimo de família, filhos, etc.). Após, durante a audiência de apresentação perante o Ministério Público também foi questionado sobre estudo, trabalho, além de perguntas a respeito dos pais e sobre a vida dos adolescentes. Apenas um adolescente não era da cidade, e estava aqui para fazer tratamento médico pelo uso de 
substâncias entorpecentes em uma Fazenda Terapêutica, mas fugiu.

Em virtude da atuação da Defensoria Pública e da nomeação de advogado dativo (remunerado pelo Estado), supõe-se que eram de situação financeira deficitária, além das informações prestadas por eles próprios no Ministério Público e perante o Juiz.

Como já salientado as condutas infracionais foram roubo (subtração de um celular com uso de arma branca - faca), e duas tentativas de homicídio qualificado (com desferimento de tiros e golpes de faca, soqueira e socos).

Todos os processos seguiram os mesmos procedimentos havendo apenas alguma modificação na fase inquisitorial, mais propriamente na Delegacia de Polícia, como o reconhecimento por fotografias, levantamento fotográfico e exame de corpo de delito. A Delegacia de Polícia civil foi o órgão responsável pela elaboração do Procedimento Especial de Adolescente, onde realizou-se o Boletim de Ocorrência e todos os atos investigatórios iniciais do ato infracional. Foi realizado o PEA (Procedimento Especial de Adolescente) encaminhado ao órgão do Ministério Público (M.P.), órgão acusatório, que realizou as Representações perante o Poder Judiciário dos adolescentes em conflito com a lei, além de apresentar as alegações finais requerendo as internações (este órgão realizou, também outras diligências, as entrevistas com os adolescentes e seus responsáveis legais).

As representações foram recebidas pelo Juiz da Infância e Juventude, que instaurando as ações judiciais, chamou (citação) os adolescentes para apresentarem suas defesas (instaurando o contraditório e a ampla defesa), para ao final, formar a sua convicção e julgar através de sentença (condenando ou absolvendo). As defesas dos adolescentes foram promovidas através da Defensoria Pública e, em um dos casos, através de Defensor Dativo (nomeado pelo Juiz e ressarcido pelo Estado).

Ressalta-se que às defesas técnicas é facultado requerer as provas que entender necessárias ao deslinde do feito, tais como perícias, estudos sociais, laudo psicológicos e médicos, entre outros. Nesse sentido, somente em um processo $(030 \backslash 3)$ foi requerido laudo social pela defesa, sendo deferido pelo Juiz. Neste mesmo processo foi juntado o laudo psicológico do adolescente realizado durante a internação provisória.

Vários profissionais atuaram nos processos, a saber, o Promotor de Justiça (MP), servidores do cartório, o Delegado de Polícia Civil, Policiais civis, peritos (laudo de avaliação e identificação), papiloscopista, Conselheiras Tutelares; Juízes (Poder Judiciário), oficiais escreventes, oficiais de justiça, escrivães e Defensor Público (Defensoria pública), além de advogado dativo. Em apenas um dos processos houve a atuação do assistente social e do psicólogo.

Em relação aos laudos técnicos, somente em um dos processos foi requerido, pela defesa técnica, o estudo social do adolescente $(030 \backslash 3)$. No processo apenso de internação provisória, foi juntado aos autos o laudo psicológico do adolescente que estava internado provisoriamente na FASE. Nesses dois laudos há indicação dos 
profissionais acerca da necessidade de tratamento especializado: "[...] sugerimos que tenha acompanhamento psicossocial e pedagógico [...]. A irmã disse que não aprendeu a ler [...]” (fls.99\100 - Estudo Social). “[... necessita de atendimento psiquiátrico [...] percebo a necessidade de atendimento psiquiátrico e psicológico [...]" (fl.54, Laudo Psicológico).

Os processos em análise foram sentenciados por Juízes diferentes. As sentenças, apresentaram as mesmas estruturas: relatório, fundamentação e dispositivo. O relatório estabeleceu toda a cronologia do processo, descrevendo todos os atos praticados. Já na fundamentação estabeleceu-se a materialidade (existência do ato infracional) e a autoria. Por fim, o dispositivo estabeleceu a procedência da representação, aplicando a medida socioeducativa de internação.

Note-se que em nenhum momento foram analisados pelo Magistrado, os laudos apresentados. Mais do que isso, em dois processos tais laudos nem sequer foram requeridos pela defesa técnica ou pelo M.P., nem tampouco pelo Juiz, mesmo com informações sobre a vida pregressa do adolescente e sua condição social. A tônica principal foi o ato infracional praticado ou a suposta gravidade do ato. Em dois processos houve efetivamente a violência real contra a vítima demonstrada através dos disparos de arma de fogo e dos golpes de faca desferidos, mas em todos os processos considerou-se tão somente a palavra da vítima que "[...] teria visto uma faca [...]", para identificar o meio utilizado no cometimento do ato infracional, sem contudo ser apreendida.

Mister se faz acrescentar que em todos os processos o único órgão que requereu, em razões finais, a internação foi o Ministério Público, e no processo 030 \3 houve a representação do Delegado de Polícia para a internação provisória, o que foi deferido pelo Juiz. Os outros profissionais que atuaram (assistente social e psicóloga), incluindo a Defensoria Pública e defensor dativo, foram contrários à segregação, inclusive, requerendo a aplicação de outra medida menos gravosa (liberdade assistida). É necessário salientar que o Magistrado não está adstrito à opinião dos técnicos, mas deve fundamentar a sua decisão. Assim, forçoso concluir que, nestes processos, as sentenças basearam-se unicamente no ato infracional, sem nenhuma alusão às circunstâncias, nem a capacidade de cumprimento da medida. Vejamos parte da sentença (fundamentação) do processo $030 \backslash 1$, onde o fato delitivo foi roubo,

[...] destarte, julgo procedente a representação, pois a autoria e a materialidade da infração estão confirmadas pela prova coligida ao feito, não havendo qualquer circunstância ou excludente de ilicitude que autorize o afastamento da aplicação da medida socioeducativa. A medida socioeducativa requerida pelo Ministério Público é adequada e proporcional aos fins a que se destina, pois previstas no ECA como meio de corrigir a inclinação delitiva demonstrada pelo adolescente com seu ato, segundo as regras normais da sociedade. Então, essa medida embora severa, se mostra imprescindível, por seu cunho educativo e pedagógico, porquanto conferido pelos antecedentes de fls.34 e por este fato, o desvio de conduta por pessoa em fase de formação de valores, suscetível de reeducação moral e social. Assim, aplico ao adolescente a medida socioeducativa de internação sem atividades iniciais externas (art.122, I, do ECA - por se tratar de ato infracional cometido mediante grave ameaça) 
Há menção aos princípios norteadores do ECA, principalmente à Doutrina da Proteção Integral ao referir o adolescente como pessoa em fase de formação de valores (sujeito de direitos), bem como ao princípio da proporcionalidade. No entanto, há um flagrante descompasso, frente à Doutrina mencionada porquanto, em nenhum momento, essa "Pessoa em fase de formação" é colocada no centro do estudo. Analisa-se o fato delituoso, a autoria e a materialidade, deixando-se ao "relento", todas as demais circunstâncias, como família, estudo, trabalho (informações que o próprio Magistrado questiona no interrogatório).

Pessoa em formação, mas pergunta-se: onde o Magistrado e o órgão do MP utilizam a Doutrina da Proteção Integral? É certo que em todo processo judicial há o efetivo cumprimento da legislação, principalmente com a nomeação obrigatória de defensor, considerando a obrigatoriedade constitucional do devido processo legal, do contraditório e da ampla defesa, havendo possibilidade de desvendar o ato infracional e quem o praticou. Mas a referida Doutrina sugere que se vá além desses simples atos, necessita que haja uma visão geral e específica, mostrando possibilidades de inserção, pedagógicas, psicológicas e inclusive médicas.

A internação ligada à cunho pedagógico e educativo, destoa do paradigma da Doutrina. $\mathrm{O}$ processo judicial, nesta visão, cumpre todo o formalismo da legislação, mas inclina-se ao retorno da Doutrina “menorista", já superada com a entrada em vigor do ECA.. Salienta-se que o processo judicial é imperioso. A defesa técnica imprescindível e nesta, a busca de elementos outros (estudo social, pedagógico, psicológico, médico e tantos outros) que identifiquem o motivo real do cometimento da infração é uma exigência da própria normativa que prevê a doutrina da proteção integral. Além destes e primordialmente, a atuação do Magistrado deve estar voltada para à Pessoa em formação, com a aplicação de medidas que realmente o coloquem em situação de formação de valores, utilizando o poder discricionário que detém para alavancar um sistema, embasado na intervenção de técnicos (olhar psicossocial) que realmente afira as condições pessoais e sociais do adolescente visando o cumprimento da medida e a utilidade desta.

\section{CONSIDERAÇOES FINAIS}

Com o advento da Constituição Federal de 1988 (alicerçada nos princípios da igualdade e dignidade da pessoa humana), Lei Magna brasileira, baseada na Convenção sobre os Direitos da Criança e regulamentada pelo Estatuto da Criança e do Adolescente estabeleceu-se um novo paradigma relativamente a criança, ao adolescente e ao adolescente em conflito com a lei. Erigiu-os à condição de sujeitos de direitos (refletida na condição especial de pessoa em desenvolvimento), abarcados pela Doutrina da Proteção Integral.

Relativamente à aplicação da medida socioeducativa, o ECA preconiza um critério diferenciado (art.112), baseado no princípio de individualização e no princípio da condição peculiar de Pessoa em desenvolvimento, além de facultar ao julgador a aplicabilidade da medida mais adequada ao caso concreto, 
considerando a capacidade do adolescente, as circunstâncias e a gravidade da infração (art.1 12,\$1 ${ }^{\circ}$ ). Ou seja, não há critérios estritamente taxativos ou objetivados para serem aplicados diante da situação infracional, tendo em vista a supremacia dos princípios em questão, que, portanto, deveriam levar ao juiz analisar o quadro geral deste processo de desenvolvimento.

Com base nessas premissas, pesquisaram-se os critérios utilizados pelo julgador, em casos concretos constantes em três processos que tramitaram na Vara da Infância e Juventude da comarca de São Borja, percebendo-se que em apenas um dos processos houve a emissão de laudo psicológico e do estudo social. Nos outros dois, nem sequer foram requeridos pela defesa documentos outros que pudessem justificar a condição especial do adolescente em conflito com a lei. Vários profissionais participam do processo envolvendo a investigação do ato infracional e toda a marcha procedimental até a conclusão derradeira da sentença.

Relativamente aos laudos apresentados, estes não foram considerados pelo Juiz, nem tampouco foi fundamentada a sua não apreciação. Ressalte-se que não há obrigatoriedade da decisão judicial estar vinculada aos laudos considerando o poder discricionário do Juiz ao relatar a sentença, mas surpreende o fato de haver ignorado completamente a existência de tais documentos e não fundamentar a razão da sua não utilização na aplicação da medida socioeducativa de internação. Como individualizar a medida, se a história de vida individual de cada adolescente não é considerada?

As representações apresentadas pelo Ministério Público foram julgadas procedentes e aplicou-se a medida socioeducativa de internação, nos casos de roubo e tentativa de homicídio, sendo que o foco da decisão judicial baseou-se unicamente no fato ocorrido e na gravidade do ato infracional. Não foram avaliadas outras possibilidades de inclusão do adolescente em conflito com a lei em programas sociais em substituição à medida socioeducativa de internação, nem tampouco considerados os critérios sociais, familiares e educativos apontados pelos profissionais que atuaram no processo para minimizar a adoção da medida. Com isso, a função pedagógica da medida, com objetivo de transformar a situação real do adolescente, não fora respeitada.

O ECA não previu expressamente (como no Código Penal) a forma de aplicação das medidas socioeducativas, razão pela qual o Juiz exerceu plenamente a sua discricionariedade, ainda que ferindo o Princípio da Legalidade - pois não justificou a decisão segundo os critérios. De igual forma, fere também esse princípio ao não analisar as circunstâncias e a capacidade do adolescente em cumprir a medida de internação, ampliando sobremaneira a intervenção do Estado na esfera individual do jovem, sob o argumento de que sua atuação é "ressocializadora e educativa".

Embora o Brasil seja signatário das Convenções e Tratados internacionais e a legislação Pátria enumere princípios fortalecedores da dignidade da Pessoa humana, assistimos a uma profusão de decisões que balizam-se pelo formalismo, deixando de se considerar a necessária garantia de direitos. Princípios legais feridos foram 
identificados nessa amostra e não só eles, mas vidas foram feridas, quando não se oportunizou a análise de cada circunstância do meio em que o adolescente infrator estava inserido. Pessoas em condição peculiar de desenvolvimento em busca da propalada Doutrina da Proteção Integral que se estampa na lei escrita, tão somente e se dilui no cotidiano das fundações de atendimento socioeducativos "sem atividades externas".

Nesta pesquisa, fora possível observar uma literatura bastante avançada no que diz respeito aos Direitos da Criança e do Adolescente, destacando-se a Doutrina da Proteção Integral. Contudo, os principais avanços encontrados na literatura não embasaram a práxis do Juiz, impedindo a garantia de uma justiça plena. Ora, como nos ensina Bobbio, na Era dos Direitos, "[...] em se tratando de Direitos Humanos o problema que nos aflige não é tanto de fundamentação destes Direitos, e sim, fundamentalmente, da implementação destes Direitos". ( 2010, p.177).

\title{
WHY ARE YOU PUTTING ME IN? A STUDY ON THE CRITERIA USED FOR THE IMPOSITION OF THE SOCIO-EDUCATIONAL MEASURE OF HOSPITALIZATION IN THE REGION OF SÃO BORJA
}

\begin{abstract}
The analysis of the criteria used by the Judge of Childhood and Youth for the application of the socio-educational measure of hospitalization to the adolescent in conflict with the law is the subject of this study. Three judicial proceedings were analyzed, with final decisions, in the District of São Borja-RS, with sentences rendered by different judges, where they were hospitalized. The governing legislation of the subject - Federal Constitution and Statute of the Child and Adolescent -, erected the adolescent to the condition of subject of law, considering him person in peculiar condition of development, adopting a differentiated criteria for application and execution of the socio-educational measure (Doctrine Of Integral Protection), extending the discretion of the Judge of Childhood and Youth. Although the vanguard of doctrine, based on fundamental principles, is diluted in the effective application to the concrete case, by the use of subjective parameters of the judge that dispenses with essential elements (circumstances), besides the non-observance of technical referential issued by other professionals, such fact results in an affront to the guiding principles of the Statute of the Child and the Adolescent and the restriction of the numerous guarantees to the adolescent offender.
\end{abstract}

Keywords: Adolescents; Infringement Act; Socio-educational measure; Discretionary

\section{REFERÊNCIAS}

BOBBIO, Norberto. Teoria do ordenamento jurídico. 10. Ed.. Brasília: Ed.UNb, 1999.

BRASIL. Constituição (1988). Constituição da República Federativa do Brasil. Brasília, DF: Senado,1988. Decreto/Lei $\quad \mathrm{n}^{\circ} \quad 2.848 \backslash 40$. Código Penal Brasileiro. Disponível em 
<http://www.planalto.gov.br/ccivil_03/decreto-lei/Del2848compilado.htm . Acessado em 26\06 2016.

PEC 171 \1993. Câmara dos Deputados. Dispõe sobre a redução da maioridade penal. Disponível em

$\overline{<h t t p: / / w w w . c a m a r a . g o v . b r / p r o p o s i c o e s W e b / f i c h a d e t r a m i t a c a o ? i d P r o p o s i c a o=14493 \geq . ~ A c e s s a d o ~ e m ~}$ $20 \backslash 06 \backslash 2016$.

DIGIÁCOMO, Murillo José. Breves considerações sobre a proposta de Lei de Diretrizes Socioeducativas. Curitiba: MIMEO,2002.

Criança acusada da prática de ato infracional: como proceder? Disponível em <http://www.mppr.mp.br/arquivos/File/Criancaacusadadapraticadeatoinfracional.pd $\geq . \quad$ Acessado em $20 \backslash 06 \backslash 2016$.

FERRAZ JUNIOR, Tercio Sampaio. Teoria da norma jurídica: de pragmática da comunicação normativa. 3a. Ed.. Rio de Janeiro: Forense, 1999.

GONÇALVES, Maria Dinair Acosta. Proteção Integral: paradigma multidisciplinar do Direito Pós - Moderno. Porto Alegre: Alcance, 2002.

JUNQUEIRA, Ivan de Carvalho. Ato Infracional e Direitos Humanos: A internação de adolescentes em conflito com a lei. Campinas $\backslash$ SP:Servanda Editora, 2014.

LAZARROTTO, Gislei Domingas Romanzini. Medida socioeducativa: entre A\&Z. Porto Alegre: UFRGS, 2014.

LIBERATI, Wilson Donizeti. Adolescente e ato infracional: medida socioeducativa é pena? 2a. Ed.. São Paulo: Malheiros Editores, 2003.

CONSELHO REGIONAL DE PSICOLOGIA - SP - Manual de Elaboração de Documentos Decorrentes de Avaliações Psicológicas. Disponível em <http://www.crpsp.org.br/ \. Acessado em 17\06\2016.

MATOS, Priscila Santini de. Aplicabilidade e eficácia das medidas socioeducativas impostas ao adolescente infrator. Disponível em: <http://tcconline.utp.br/wp-content/uploads/2012/05/APLICABILIDADE-EEFICACIA-DAS-MEDIDAS-SOCIOEDUCATIVAS-IMPOSTAS-AO-ADOLESCENTE-INFRATOR.pdf.> Acessado em 01 de mar de 2015.

MORAES, Roque. Uma tempestade de luz: a compreensão possibilitada pela análise textual discursiva. Disponível em: <http://www.scielo.br/pdf/ciedu/v9n2/04.pdf.>Acessado em 10/04/2015.

ROESCH, Sylvia Azevedo. Projetos de estágio e de pesquisa em administração. $3^{a}$ Ed.. São Paulo: Atlas, 2007.

ROSSATO, Luciano Alves. Estatuto da Criança e do Adolescente comentado. São Paulo: Ed. Revista dos Tribunais: 2010.

SANTOS, Marileide Porto dos. A discricionariedade do juiz na aplicação e execução da medida socioeducativa de internação. Disponível em: <http://www.unibh.br/revistas/ecivitas/>. Acessado em 01 de mar de 2015.

SARAIVA, João Batista. Direito Penal Juvenil. Disponível em: <http://www.unijui.edu.br/arquivos/clinicapsicologia/informativos/falandonisso16/opiniao.pdf >. Acessado em 01 de mar de 2015.

Compêndio de direito penal juvenil: adolescente e ato infracional. 4a. Ed. Porto Alegre: Livraria do 
Advogado Editora, 2010.

$\mathrm{O}$ adolescente em conflito com a lei e sua responsabilidade: nem abolicionismo penal nem direito penal máximo. Revista Brasileira de Ciências Criminais, São Paulo: Revista dos Tribunais, ano 12, n. 47, p. 138-140, 2004.

VILLAS - BÔAS, Eduardo da Silva. Direito Penal e o paradigma da responsabilidade juvenil: ato infracional, medida socioeducativa e direitos fundamentais. Salvador: EDUFBA,2012.

VOLPI, Mário. O adolescente e o ato infracional. 6ª. Ed. São Paulo, Cortez, 2006.

RIO GRANDE DO SUL, Tribunal de Justiça. Apelação Cível No 70063219299, Sétima Câmara Cível, Relator: Sérgio Fernando de Vasconcellos Chaves, Julgado em 25/02/2015, jurisprudência, disponível em <http:www.tjrs.jus.br/site/jurisprudencia/>. Acessado em 19 de junho de 20016.

Trabalho enviado em 08 de junho de 2017.

Aceito em 09 de setembro de 2017. 